\title{
Significance of Interdisciplinarity in Varied Pedagogical Contexts in English Studies
}

Yadukrishnan $\mathrm{P} \mathrm{T}^{*}$ and Nikhil Govind ${ }^{\dagger}$

\section{Abstract}

This article is an experiential insight into the undergraduate and postgraduate education in English Studies. It can be considered as a vantage point from which certain prevalent institutional questions may begin to be raised. While there is a clear policy imperative on interdisciplinarity, the category makes little sense unless there is a strong sense of the terrain on which such ideas may be foisted. Therefore, an evaluation in terms of studentgrounded reality of capacity, institutional breadth and actual faculty strengths and limitations is essential. The paper is an analysis from the 'demand side' that is a doctoral student, who engages with how such attempts are received by the student. Future research could study how widely applicable this is to the various scales and types of universities.

Keywords: English Studies, Interdisciplinarity in Humanities

\section{Introduction}

Today, universities and policy making bodies in India have a fairly good theoretical knowledge of what they should be doing. To take

\footnotetext{
* Manipal Academy of Higher Education (MAHE), Karnataka, India; yadu19@gmail.com

† Manipal Academy of Higher Education (MAHE), Karnataka, India; nikhilgovind@hotmail.com
} 
one example, inter or multi-disciplinarily is a word with much currency in accreditation and pedagogy circles. No policy maker or professor speaks more than a few sentences before stumbling on this term. Yet, once one scratches the surface, one realises that it is hard to actually perform interdisciplinarity at an institutional level. Universities are conservative bodies where seniority largely rules, and where the Professor seems to be profoundly removed from the $\mathrm{PhD}$ candidate or research scholar. Given such a scenario, how can a generation that has not grown up on interdisciplinarity teach the same to a younger and different generation? In English Studies, the reason that many teachers still go on teaching Dryden is that they simply repeat ancient notes (perhaps from the time of Dryden himself!), or use a more updated guidebook. India has never produced a Dryden scholar, so at one level this is puzzling (we are more loyal to the colonial era than even the British), and at another level, it is easily explained (the guidebooks and notes do all the work). The paradox of English Studies in India is that many professors would rather teach something remote like Dryden for the aforementioned reasons than the everyday literary culture that surrounds them; that culture may be that of Kannada, or the smartphone, or the repackaging of religious myths into electoral nationalism. It is clear that we have to re-interpret and re-imagine interdisciplinary English and Cultural Studies for both Indiacentric research, as well as learn to attune it to the institutional and pedagogical minutiae of the classroom. The true test of success would be if a student today felt a visceral 'opening of the mind' ideally, a student who has come from a more traditional syllabus, evaluation and pedagogical apparatus. The doctoral student Yadukrishnan $\mathrm{P} \mathrm{T}$, who has written the article below, finely articulates what it is like to breathe in this grounded interdisciplinarity. He contextualises his intellectual growth in terms of the colleges he had studied in before; there were the challenges of communicating in English where it was not the naturally spoken language for most of those from non-elite backgrounds; he had to learn to think across courses and disciplines rather than just within them; he had to learn how the classroom space is also an ethical space where texts which make us uncomfortable must nevertheless be read with charity, and sometimes with extra-classroom engagement. His current doctoral work is on the dynamics of caste 
in Malayalam cinema of the nineteen eighties and nineties - thus one can see that though no one had taught him Malayalam cinema, he was able to take a certain spirit of interdisciplinary thought (from English, but also History and Sociology) and apply it skillfully to an area that has obvious social and cultural significance, but which film and cultural scholarship has hitherto eschewed. Thus, this paper is less concerned with a fixed definition of interdisciplinarity. Rather than seeking universalisation, this paper highlights interdisciplinarity as an open mode of thinking understood through the trajectory of an individual doctoral scholar's intellectual quest.

This pattern of not explicitly addressing the strengths of the Humanities (critical thinking, multiple intelligences, collaborative methodologies) bedevils through high school, undergraduate and postgraduate education even today. An awareness that Humanities is not just a set of texts but also new modes of thinking is what needs to be addressed, and forms the rationale of the following inquiry. The approach is deliberately qualitative and experiential in its methodology and objectives. The use of one institute, as an illustration, is not to generalise or claim transferability across types of institutions, but to raise one set of pertinent questions as raised by an individual researcher. It is outside the purview of this paper to study practices in English Studies in multiple educational contexts and institutions in India. However, there is no doubt that cross-comparative research can complement and modify the current account, and one hopes to see more such work emerge in the future.

I studied in one of the schools which did not provide Humanities as a stream in its 11th and 12th grade. After my 10th board exam, a decision had to be made between Science and Commerce. My school was situated in North Kerala district of Malappuram and was under the Central Board of Secondary Education (CBSE). After the 10th board exams, many of my friends got themselves transferred to schools in the neighbouring district, Thrissur so as to attend the famous P. C. Thomas coaching camp for either Medicine or Engineering. I did not want to pursue either of these courses. Neither was I passionate about pursuing physics, chemistry or biology. My parents had previously, to their dismay, attempted to 
push my elder brother, who was a better student, into the entrance exam frenzy. Consequently, when I told them that I did not want to pursue science, they were supportive. I chose commerce as the stream for my secondary education, but even at that time, I knew that I wanted to pursue humanities. Not only was humanities missing for the higher secondary students in my school but also was never talked about as any form of option for higher education.

In school, English is often taught in a mechanical manner, where the focus can be solely to ensure effective communication among students in English. In fact, CBSE schools like mine took its relationship with the English language a bit too far by banning students from even speaking in the regional language within the school premises. The argument was that this was the only way students would familiarise themselves with the language which was supposed to be their salvation in the job market. This did not work, for it only amplified the appeal for speaking in Malayalam within the school premises. I remember the years in which my school collaborated with a Bangalore based organisation called ILM (Institute of Language Management) to make sure students communicated in English. There were posters and signboards all over the school which said "ILM says speak in English" and there were ILM executives walking around in the school premises making sure the students were always doing so. This annoyed the students even more. English as a subject in school was thus reduced to mere communicative skills, where even while teaching English literature the teacher was never interested in inculcating critical thinking or encouraging the students to look into the craft of the writer. Even discussions and debates in classrooms about specific literary works were mostly judged based on whether the student was well versed in the language. Apart from being an unhelpful way to teach literary texts, this approach also alienated a lot of students coming from different social backgrounds. Many students had the privilege of having parents who were educated, and who could help the student with different subjects at home, including English. These students were visibly at an advantage over students who were often the first member in their family to receive a higher secondary education. The school was mostly unsympathetic to this reality and simply expected every single student to perform equally, for in their eyes, they were all receiving 
equal training. Because of all this, many of the students never thought about pursuing humanities. They saw no merit in pursuing it, apart from gaining a degree. Subjects like sociology, philosophy, political science and so on were never part of the school curriculum so most students did not bother looking into it, and English as a subject in the course of the years was reduced to mere functionality whereby taking it up for higher education seemed pointless to everyone. The only reason I could choose BA English after my 12th board exam was because my mother was once an English lecturer and was supportive of me.

For my BA program, I joined a prominent aided college under Calicut University. My batch consisted of students who were chiefly from the State board and most of them were passionate about a Humanities education. This is even though we were rarely made conscious about the fact that we were pursuing an integrated Humanities education, partly because of the lack of communication between different humanities disciplines within the campus. There was always an implicit hierarchy between the departments of english, sociology, philosophy and history. The English department was in many ways isolated, and the pedagogy was dated. Written assignments were not a significant part of the curriculum and the syllabus was almost the same for the last couple of decades. The senior lecturers in the college used to bring their old notes from the time they had studied the same text decades before. Our syllabus included courses such as 'Reading Prose', 'Reading Drama', 'Reading Poetry', 'Modern English Literature', 'World Classics in Translation', 'Indian Writing in English' and so on. The entire syllabus was set by the University, and neither the specific college, its department nor the course instructors had much of a leeway to make changes. However, a good thing about the pedagogy in this college was that it catered to students from different economic and social backgrounds. Classes were often taken in Malayalam to make different aspects of different texts accessible to each student. This really helped to make the subject available to a wider category of students. But the texts were dealt in complete abstraction and no attempt was made to contextualise it in any meaningful manner. BA English students had to take a course on British history along with courses dealing with Literature and Drama in the Elizabethan Era but these two subjects, even though structured to complement 
each other, never came into dialogue. Both subjects were taught in isolation, defeating their purpose. At the centre of these issues, lay the written exam format, which was incapable of nourishing a good humanities education. A student could skim through study guides for an already de-personalised textbook one day before the examination and manage to get a passing grade. This was not the fault of the college I happened to study in, but rather of a system that many colleges still follow. There were no attempts at providing any form of writing training for students, and this visibly impeded the way he/she approached any text. This is in addition to the fact that these disciplines were being taught in vacuo, and following a syllabus which requires considerable updating.

I did not want to continue my postgraduate education under the same system and wanted to pursue something different. When I applied for my Masters in English in Manipal Centre for Humanities $(\mathrm{MCH})$, I was informed that this programme was interdisciplinary in nature. When I joined $\mathrm{MCH}$ in 2015, I was unsure of what this concretely entailed. $\mathrm{MCH}$ at the time offered 3 streams-philosophy, sociology and English. Having chosen English, I had to take one course each from Philosophy and Sociology, along with two courses in English in both the first and second semesters. This approach was effective, for texts, lectures, courses and subjects were communicating with each other in a way I had not seen before. $\mathrm{MCH}$ did not have exams at the end of the semester-instead, students were asked to write properly cited periodic assignments throughout the course duration. At the end of every semester, we were asked to write a 5000-word term paper for each course. The fourth and final semester focussed on developing an original MA dissertation of 30,000 words. Students chose their thesis instructors, set periodic deadlines, and worked towards finishing the work in the stipulated time.

In my first semester, Dr. Nikhil Govind taught a course titled 'Reading and Writing' which began with Urvashi Butalia's The Other Side of Silence: Voices from the Partition of India (1998). For an English student coming from a very traditional undergraduate department, this text and the very nature of the course felt unorthodox. We were asked to read the first three chapters of the text for the first class and were asked to contribute to class 
discussion. The class was not conducted in the form of a long lecture and was more interactive. There were some students in the class who had grandparents who experienced partition personally, and these students brought in different perspectives that were very enlightening. This was a completely new experience for me. This course also included texts like Priyamvada Gopal's Literary Radicalism: Gender, Nation and Transition to Independence (2005), Aamir Mufti's Enlightenment in the Colony (2007) and Vinayak Damodar Savarkar's Essentials of Hindutva (2017). The final text, in particular, was very interesting to engage with - for the majority of us in the class did not (and still do not) feel comfortable with its ideology. But the discussions in class made us engage with it nevertheless and properly articulate our concerns with it. What I really appreciated about this course was the fact that it cultivated a certain respectful and ethical way of approaching a text. This was also a point of importance in the philosophy course that was being taught by Dr. Apaar Kumar at the time titled 'Nature and Reality' where, while engaging with pre-Socratic texts on metaphysics, students were encouraged to approach every single text and every single argument with charity.

In the second semester, Dr. Gayathri Prabhu took a course titled 'Political and Spiritual Rhetoric' (Course Structure (MAEnglish/Philosophy/Sociology Syllabus at MCPH, n.d.) which delved into various concerns of twentieth-century India through a variety of genres - novel, autobiography, public discourse and so on. In some ways this course brought in a linearity to many of the questions that were explored in the previous semester, especially 'Reading and Writing'. For example, Bankim Chandra Chatterjee's Anandmath (2019/1882) which was part of this course, added dimensions to Essentials of Hindutva (2016) by Savarkar discussed in the previous semester. Political and Spiritual Rhetoric involved reading the primary texts of several key figures in early 20th century India. These texts were read in parallel, and thematic connections were drawn between them. Some of the texts discussed included Jawaharlal Nehru's Discovery of India, Rabindranath Tagore's Home and World (2005/1916), B.R Ambedkar's Annihilation of Caste (1936/2014), Bhagat Singh's "Why I am an Atheist" (2019) and Lalithambika Antharjanam's "Admission of Guilt" (2017). This course in many ways solidified my interest in academia, for I was 
struck by the notion of reading political texts as literature, instead of solely attempting to understand and critiquing its ideology. The course encouraged students to closely read different segments of the text so as to break it down and try to understand not just 'what' that was being conveyed or argued by the writer, but also 'how' it was done. Dr. Gayathri Prabhu pointed out the lack of scholarship in many of the works of these writers and encouraged students to work in this field. The writings of Bhagat Singh caught my interest in this course and I wrote a term paper on his political tracts, a topic that I continued to explore later for my MA thesis.

It was in the third semester that all the different courses seemed to strongly converge. This was the semester in which Dr. Anindita Majumdar was teaching a course called "Medical Anthropology" (Course Structure (MA-English/Philosophy/Sociology Syllabus at $\mathrm{MCPH}$, n.d.). At the same time, Dr. Gayathri Prabhu was teaching "Medical Humanities" (Course Structure MAEnglish/Philosophy/Sociology Syllabus at MCPH, n.d.), which at times overlapped with the "Gender and Sexuality" course (Course Structure MA - English/Philosophy/Sociology Syllabus at MCPH, n.d.) that was being taught by Dr. Nikhil Govind. Since students were already in their third semester, they were not required to take courses outside their discipline. However, because of the way these courses aligned itself, many students took up extra courses. I remember how vibrant this semester was in $\mathrm{MCH}$ where issues pertaining to mental illness, sexuality, medicine, and gender were being discussed and looked at in the most intersectional sense. Dr. Gayathri Prabhu insisted that for the midterm assignment, English students had to take the course outside the classroom. Manipal is the most important medical hub in the region, having originated from the medical school that was set up in 1953. Dr. Gayathri Prabhu encouraged students to move away from abstract thought and pure textual analysis, and instead have productive conversations with the medical community in Manipal. We were required to prepare a project based on this experience. For this, I volunteered for a month in Hombelaku Psychiatric Rehabilitation Centre, a unit of Kasturba Medical College, Manipal, and extensively interacted with two patients suffering from paranoid schizophrenia. This was a formative experience for me as it brought into the forefront several questions pertaining to the ethics of 
writing and research. It also brought to the fore the question of the writer/researcher's subject position. All the students later read out their work in the class, and this entire exercise was extraordinarily rewarding for me.

The fourth semester had only two courses, and instead of term papers, students had to finish their 30,000-word MA dissertation. I worked under the supervision of Dr. Gayathri Prabhu on the writings of Bhagat Singh. What I noticed in this semester was how every single course that I took in $\mathrm{MCH}$ had informed my understanding of the thesis I was writing. Dr. Gayathri Prabhu had ten students working under her for the MA thesis and she had deadlines for them set periodically throughout the semester. She provided detailed feedback on every submission. The last few weeks of this writing process only further confirmed my interest in academia, and I personally am very content with the work I was able to accomplish in this time period. I continued to extend and revise my thesis even after my submission, and it was recently published as a monograph this year by a university press. It is this focus on training in writing, on critical thinking and on interdisciplinarity that makes me approach humanities education today, more passionately.

\section{References}

Ambedkar, B. R. (1936/2014). Annihilation of caste: The annotated critical edition. Verso Books.

Bhutalia, U. (1998). The other side of silence: Voices from the partition of India. New Delhi, India: Penguin Books India.

Chatterii, B. C. (2019/1882). Anandamath. Orient paperbacks.

Course Structure (MA-English/Philosophy/Sociology Syllabus at $\mathrm{MCPH}$. (n.d.) Manipal Centre for Higher Education. https:// apply.smude.edu.in/content/dam/manipal/mu/mcph/Documents/ MA-Course\%20Structure.pdf

Gopal, P. (2005). Literary radicalism in India: Gender, nation and the transition to independence. Hoboken: Taylor and Francis.

Gopal, P. (2012). Literary radicalism in India: Gender, nation and the transition to independence. Routledge: UK.

Mufti, A. R. (2007). Enlightenment in the colony: The Jewish question and the crisis of postcolonial culture. Princeton: Princeton University Press.

Nehru, J. (2008/1946). Discovery of India. Penguin UK. 
Raveendran, P. P., \& Jayasree, G. S. (Eds.). (2017). The Oxford India Anthology of Modern Malayalam Literature: Poetry, drama, and prose. Oxford University Press.

Savarkar, V. D. (2016). Essentials of hindutva. Retrieved from http:/ /library.bjp.org/jspui/bitstream/123456789/284/1/Essentials \%20of\%20Hindutva.pdf

Singh, B. (2019). Why I am an atheist. General Press.

Tagore, R. (2005/1916). Home and the world. Penguin Books India. 